\title{
Investigation of Uniformity of Allowance along Airfoil of GTE Turbine Blade
}

\author{
R. A. Vdovin* \\ Samara University, 34, Moskovskoe sh., Samara, 443086 Russia
}

\begin{abstract}
This paper shows the results of a study of the uniformity of the allowance along the airfoil in the turbine blades workpieces. It is found that in the existing industry, there is a defect associated with a lack of allowance along the airfoil (from the blade back and pressure side) for the polishing operation in order to give the required cleanliness and roughness of the surface layer. By measuring the wall thickness of the blade airfoils, it is concluded that by mechanically modifying the technological bases on the blade, it is possible to select the optimal position of the workpiece in the template instrument, at which the allowance along the airfoil is relatively uniform, and the dimensions of the blade wall thickness will be within the specified tolerance.
\end{abstract}

\section{Introduction}

The accuracy of the parameters of the technological process of manufacturing the GTE turbine blades is characterized by the control of the airfoil of the blade workpiece. The control of blade castings is carried out primarily to reveal any internal and external defects in the metal of the blades and to check the completeness of removal of core ceramic residues in castings.

Technological operations on creating blade models, forming the inner cavity of the casting mold during the application of a refractory ceramic coating, subsequent drying and calcining of this mold create the necessary accuracy of the blade airfoil and its position relative to technological bases [1-3].

The most important operation is to control the wall thicknesses from the blade back and pressure side of the turbine blade, since it is the inner surface of the blade that forms the main gas-dynamic characteristics of the engine, and the wall thicknesses, in particular, affect the values of such characteristics. Thus, a blade wall thickness that is too small can contribute to the early burnout of the blade and, therefore, to underestimated engine thrust values. For this reason, strict requirements for tolerances are imposed on the profile of the blade workpiece during the inspection process - from \pm 0.2 to $\pm 0.4 \mathrm{~mm}$ in different sections of the blade back and pressure side of the blade workpiece.

It is possible to solve the problem of uniform distribution of the allowance in the GTE turbine blades workpieces by some constructive methods, improving the design of the template instrument, adding several degrees of freedom, due to which the blade workpiece

\footnotetext{
* Corresponding author: vdovin.ssau@gmail.com
} 
acquires the ability to move along three axes and rotate about each of them. This design solution will be relevant for 5\% of blades, which today are rejected in batch production according to the criterion of the lack of uniform distribution of the allowance along the airfoil (i.e., by the presence of a negative allowance), since it will make it possible to transfer these blades from the category of defective to the category of suitable ones. [4].

\section{Experimental}

In the process of pouring molten metal into a ceramic mold and its crystallization, the geometric parameters of the original blade blank change. Systematic components of these errors are taken into account when finishing models, forms, and modes of the technological process. Analytical determination of these errors is difficult [5-7].

For this reason, in the design of the tooling, choice of technological modes, appointment of methods and means of fulfilment of the elements of the original workpiece, analytical and statistical dependences obtained in the process of theoretical and experimental studies of the manufacture of the initial turbine blade workpiece are used.

The dimensions of the inner cavity of the blade cooling are determined by the quality of the following operations:

- making a ceramic core in a mold;

- drying in an oven and subsequent straightening (if necessary).

During these operations, the required dimensions of the ceramic rod are formed, taking into account any possible shrinkage and warpage during the drying process. When positioning the rod in the cavity of the mold (when forming the master model of the blade from urea), errors arise that affect the position of the forming surfaces of the rod and, as a consequence, the dimensions of the wall thickness of the blade.

Today, in production conditions, the wall thicknesses of the blade back and the pressure side of the blade workpiece are controlled by the ultrasonic method using overhead templates. Special technological grooves make it possible to measure during serial control of blades in similar areas of blade workpieces [8-10].

The blade workpiece pressure side thickness is measured in 9 sections in areas $\delta 1$ and $\delta 2$, and the blade workpiece back thickness is measured in 8 sections in areas $\delta 3$ and $\delta 4$ (Figure 1) [11-13].

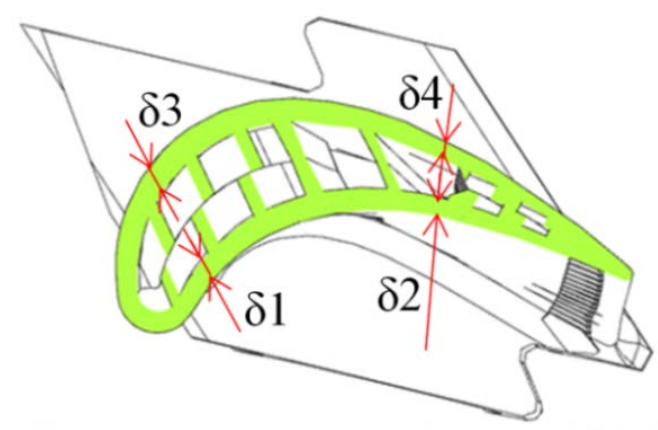

Fig. 1. Reference points for controlling the thickness of the blade back and the pressure side of the turbine blade workpiece.

The result of the control process is the determination of the value of the first maximum from the oscillograph trace, which corresponds to the distance of the transmitted and reflected ultrasonic wave. This distance will correspond to the thickness of the blade back or pressure side of the turbine blade workpiece [14]. 


\section{Materials and equipment}

Based on the $1^{\text {st }}$ stage of a high-pressure turbine containing 83 blades, the information on the values of the wall thickness along the blade back and pressure side and the tolerances on them was collected and processed by statistical methods.

Statistical investigations make it possible:

- in the process of mastering production, to determine the values of the systematic components of production errors and the random components dispersion fields, which are used to adjust the parameters of technological equipment and production modes;

- to outline design and technological measures in order to stabilize the constituent parameters of production, and to ensure the recommended values of the accuracy coefficient $\mathrm{K}_{\mathrm{T}}$.

The composition of production errors is determined by systematic constants ( $\Delta_{\text {Сист. пост. }}$, systematic time-variants $\left(\Delta_{\text {Сист. изм. }}\right.$ ), and random components $\left(\Delta_{\text {Случ. }}\right)$.

The aggregate production error $\left(\Delta_{\Sigma}\right)$, arising during the workpieces processing, is calculated by the following formula $(1)[15,16]$.

$$
\Delta_{\Sigma}=\Delta_{\text {Сист. пост. }}+\Delta_{\text {Сист. изм. }}+\Delta_{\text {Случ. }}
$$

In a batch of processed blade workpieces, the production error dispersion field will be determined by the following dependence (2).

$$
\omega_{\Sigma}=\omega_{\text {Сист. пост. }}+\omega_{\text {Сист. изм. }}+\omega_{\text {Случ. }} \leq \mathrm{T}_{\Sigma}
$$

This sum of the dispersion field should not exceed the specified tolerance $T_{\Sigma}$ for the executable parameter and should correspond to any possible permissible values. The quantitative value of the production errors dispersion field characterizes the efficiency of the production process and is determined by the dimensionless accuracy coefficient $\left(\mathrm{K}_{\mathrm{T}}\right)$.

When the accuracy coefficient makes 0.3 , the process is performed perfectly and the accuracy reserve is high; manufacturing is carried out on the new equipment, which significantly exceeds the required accuracy. The accuracy coefficient value of 0.5 indicates that the turbine blade manufacturing process is performing well; manufacturing is carried out on the equipment that is in good condition and has a normal accuracy reserve. With the accuracy coefficient value of 0.7 , it is necessary to take measures to stabilize and improve the production process; manufacturing is carried out on the equipment and with the tooling that are in normal condition with small accuracy reserve. When the accuracy coefficient makes more than 1, it indicates the presence of defects in the production process; manufacturing is carried out on the equipment and with the tooling with no accuracy reserve with an economically justified low level of scrap [17-19].

\section{Results and discussion}

Strict requirements for the execution of technological operations concerning the manufacture of turbine blades, as well as increase of the core centering accuracy in ceramic molds, improvement of operating modes of the casting installation and technological equipment allow eliminating scrap in the blade workpieces during the abovementioned operations.

For a qualitative assessment of the state of cooled turbine blades workpieces manufacture, the accuracy coefficient was determined for the characteristic points of the blade workpiece airfoil, in the calculation of which the values of the tolerances for the basic geometric parameters of the original workpiece and the probable values of possible 
dispersion fields of these parameters were taken into account. Thus, the calculated quantities have a normal law distribution.

Based on the values of the accuracy coefficient and the given recommendations, it can be concluded that the manufacture of castings of the turbine blades is carried out with a small reserve of accuracy.

Analysis of the results showed that $17.6 \%\left(\mathrm{~K}_{\mathrm{T}}<1\right)$ turbine blades workpieces with a monocrystalline structure are considered suitable, which corresponds to the production statistics of the enterprise.

The accuracy coefficient $K_{\mathrm{T}}>1$ for the rest of the turbine blade workpieces indicates the instability of the technological process and the presence of defects, both in the structure of the blade casting and in the thinning of the blade airfoil wall (a discrepancy in geometry associated with the lack of spatial distribution of the allowance in the workpieces), which increases the cost of the production process and reduces the product quality. This requires the implementation of design and technological measures to improve the technological process of manufacturing castings of turbine blades and component parts of the casting mold, as well as to reduce the scattering parameters during polishing of the blade airfoil. For this reason, the need arose to develop an algorithm for the spatial distribution of the allowance along the airfoil of the blade workpiece taking into account the finishing operation of polishing.

\section{Conclusions}

The author's analysis of the technological processes used in the production of the final shaping of the turbine blades showed that, despite significant progress of mechanical methods for formed parts processing, a number of issues aiming to ensure the required design accuracy in the manufacture of turbine blades with no allowance and weak level of production automation have not been fully resolved.

As a matter of course, the criteria for the optimal spatial distribution of the allowance along the profile were developed after they underwent experimental testing on the example of the first-stage GTE turbine blades workpieces. These criteria made it possible to methodically substantiate technological methods for the optimal spatial distribution of the allowance in the blade workpieces. Owing to the analysis, it was possible to reduce by $5 \%$ the scrap of blade workpieces resulting from uneven distribution of the allowance along the airfoil in the blades.

The research was supported by a grant of Russian Science Foundation (project No. 20-79-00254).

\section{References}

1. Dobryshkina E M, Balaykin A V, Vdovin R A and Smelov V G 2017 Fast prototyping technologies application for the compressor stator blades manufacture Opportunities and challenges of engine manufacturing development. Proceedings of the international scientific technological conference 32-34

2. Balyakin A V, Vdovin R A and Kyarimov R R 2020 Investigation of full arrangement of models on the mechanical properties of samples made from photopolymer material FullCure 720 IOP Conference Series: Materials Science and Engineering 862 (2) 6

3. Shumkov A A 2015 Fast prototyping technologies application for the medical implants manufacture Contemporary issues of science and education 2 (2) 146 
4. Vdovin R A and Smelov V G 2017 Design and optimization of the micro-engine turbine rotor manufacturing using the rapid prototyping technology IOP Conference Series: Materials Science and Engineering 177(1) 6

5. Agapovichev A V, Balaykin A V, Smelov V G and Agapovichev A V 2015 Application of additive technologies in the production of aircraft engine parts Modern Applied Science 9 (4) 151-159

6. Kiseleva A E 2017 Additive technologies application in shipbuilding design tasks Scientific and technical bulletin of Russian Maritime Register of Shipping 48-49 84-88

7. Guo N and Leu M C 2013 Additive manufacturing: technology, applications and research needs Front Mech Eng Cross Ref(View Record in Scopus Google Scholar) 8 215-243

8. Horn T J and Harrysson O L A 2012 Overview of current additive manufacturing technologies and selected applications Sci Progress (View Record in Scopus Google Scholar) 95 p. 255

9. Wong K V and Hernandez A 2012 A review of additive manufacturing ISRN Mech Eng (View Record in Scopus Google Scholar) p. 10

10. Balyakin A V, Vdovin R A and Ispravnikova S S 2020 Application of additive technologies for manufacturing turbine stator parts in aircraft engines Journal of Physics: Conference Series 1515 (4) 5

11. Pechenin V A, Bolotov M A, Ruzanov N V and Yanyukina M V 2015 Optimization of measurements of the geometry of parts with complex surfaces Measurement Techniques 58 (3) 261-268

12. Bolotov M A, Kapenkina E A, Rusanov N V and Pechenin V A 2014 Choice of production measuring instruments based on techno-economic analysis, taking into account the type I error and type II error Journal of engineering and applied sciences $(A R P N) 9$ (10) 1834-41

13. Bolotov M A, Pechenin V A and Ruzanov N V 2014 Modeling of coordinate measuring geometrical parameters form and location complexity profile of compressor blade GTE Research Journal of Applied Sciences 9 (12) 1143-48

14. Vdovin R A Designing a duplicate model of the GTE turbine blade casting process IOP Conference Series: Materials Science and Engineering 709 (3) 5

15. Singh J P and Singh R 2009 Investigations for statistically controlled rapid casting solution of lead alloys using three dimensional printing Journal of Mechanical Engineering Sciences (Proc. of IMechE Part C) 223 2125-34

16. Singh J P and Singh R 2010 Comparison of statistically controlled rapid casting solutions of brass alloys using three dimensional printing Journal of Manufacturing Technology and Industrial Engineering 1 67-77

17. Vieira L F, Paggiand R A and Salmoria G V 2011 Thermal and dynamic-mechanical behavior of FullCure 3D printing resin post-cured by different methods Proc. of the 5th Int. Conf. on Advanced Research in Virtual and Rapid prototyping vol 28 (Leiria, Boca Raton: CRC Press) pp 385-88

18. Adler Yu P 1976 Design of experiments in the search for the optimal conditions (Moscow: Science) p 280

19. Khaimovich I N and Demianinko E G 2015 Mathematical material and process simulation (Samara: SSAU) p 82 